Dossier: Judaísmo: religión, cultura, nación - Artículo original (c) (1)

\title{
Conocimiento oculto: lo apócrifo, entre los textos gnósticos y heresiológicos
}

\author{
Hidden knowledge: the Apocrypha, between Gnostic and heresiological texts
}

\author{
Mariano Alejandro Troiano *
}

\begin{abstract}
Resumen
En el presente trabajo abordaremos la noción de "apócrifo" en un sentido amplio. Este sentido abarca tanto la noción original de "oculto", existente ya en la literatura antigua, como la surgida posteriormente de "extracanónico". Nuestra metodología de análisis se desprende de los estudios cognitivos y particularmente desde el historicismo cognitivo, ya que consideramos indispensable, ubicar estos textos dentro de las estructuras mentales de los autores que les dieron origen. De esta manera buscamos comprender las representaciones existentes en los individuos que son compartidas públicamente con las representaciones de otros habitantes de la comunidad. Es decir, analizar estos textos tal cual funcionaban en las sociedades que los crearon. Así, esperamos demostrar que estos escritos "apócrifos" considerados tanto por rabinos como por eclesiásticos como "fuera del canon" y por lo tanto no determinantes para la historia y la teología, son en realidad indispensables para la comprensión del proceso de formación de dicho canon. Asimismo, estos textos conforman depósitos de sucesos, conceptos e ideas que alguna vez pertenecieron a determinados grupos tanto judíos como cristianos y que fueron luego dejados de lado en el intento de establecer un conjunto cerrado de textos que definiera cierta "autoridad" normativa para dichas comunidades.
\end{abstract}

Palabras clave: apócrifo; historicismo cognitivo; judaísmo; cristianismo; gnosticismo.

\begin{abstract}
In the present work we will approach the notion of "apocrypha" in a broad sense that encompasses both the original notion as "hidden", already existing in the ancient literatura, and the notion that emerged later as "extracanonic". Our methodology is derived from the Cognitive Studies and particularly from Cognitive Historicism, since we consider it essential to locate these texts within the mental structures of the authors that writte them. This approach let us to understand the existing representations in the individuals, publicly shared with the representations of other inhabitants of the community. That is, analyze these texts as they worked in the societies that created them. Thus, we hope to demonstrate that these "apocryphal" writings, considered by both rabbis and ecclesiastics as "outside the canon" and therefore not determinative for history and theology, are in fact indispensable for understanding the process of the canon formation. Likewise, this texts are repositories of events, concepts and ideas that once belonged to certain groups both Jewish and Christian and were then left aside in the attempt to establish a closed set of texts that defined certain normative "authority" for such communities.
\end{abstract}

Keywords: apocrypha; cognitive historicism; judaism; christianity; gnosticism.

Artículo presentado el 28 de marzo de 2018 y aprobado el 13 de febrero de 2019.

* Profesor y Licenciado en Historia (Fac. de Filosofía y Letras - Universidad Nacional de Cuyo). Profesor Jefe de Trabajos Prácticos de la Cátedra "Historia de las Ideas Políticas y Sociales I: Antigua y Medieval” y del "Seminario Historia de las Ideas Políticas y Sociales de la Edad Media" en la Universidad Nacional de Cuyo. País de origen: Argentina. E-mail: mariantro@hotmail.com 
Introducción ${ }^{1}$

A pesar de las buenas intenciones, la lectura de algunos de los últimos trabajos sobre el conjunto de escritos que componen el corpus de los denominados “textos apócrifos” revela una postura que mantiene rasgos tradicionales. ${ }^{2}$ En efecto, tanto los artículos referidos al tema como las introducciones dedicadas a los volúmenes que reunen dichos escritos definen lo “apócrifo" en oposición a lo “canónico".3 Por supuesto, se tienen en cuenta la variedad temática, geográfica, cronológica, doctrinal e incluso cultural de los componentes del corpus pero en última instancia se cae una y otra vez en la oposición “apócrifo” vs “canónico”.

Un discusión similar a la que intentamos plantear en el presente trabajo, se da también dentro de los estudios dedicados al corpus de escritos pertenecientes al judaísmo del segundo templo y el judaísmo rabínico. Ello impacta directamente en nuestro tema pues a la oposición anterior entre "apócrifo" vs "canónico" se le agrega entonces aquella de "Judaísmo" vs "Cristianismo" referida a la pertenencia de cada uno de los textos estudiados. Esta tendencia a clasificar definitivamente las fuentes antiguas es también criticada por Annette Yoshiko Reed, en su abordaje de la denominada "Pseudoepigrafía del Antiguo Testamento". En efecto, las fuentes surgidas en dicho período no pueden clasificarse homogéneamente ya que se

\footnotetext{
${ }^{1}$ Este texto utilizará las siguientes abreviaturas: AdvHaer: Adversus Haereses (Contra las Herejías. Ireneo de Lyon); ApocJn: Apócrifo de Juan (Libro de los Secretos de Juan-Nag Hammadi); ApocSant: Apócrifo de Santiago (Libro Secreto de Santiago - Nag Hammadi); Dial.: Diálogo con Trifón (Justino de Roma); EvFlp: Evangelio de Felipe (Nag Hammadi); EvV: Evangelio de la Verdad (Nag Hammadi); NH: Nag Hammadi; NHS: Nag Hammdi Studies; NHMS: Nag Hammadi and Manichaean Studies; SC: Sources Chrétiennes; Strom: Stromata (Clemente de Alejandría).

"Un caso notable es la introducción de Wilhelm Schneemelcher quien define en primer lugar el concepto de "canon", luego el de "testamento" y finalmente el de "apócrifo" en oposición a los otros dos. A pesar de ello, el autor acierta en establecer el origen de la carga negativa que la ortodoxia cristiana dará al concepto en el uso que hacen los autores gnósticos del concepto, asociándolo a sus enseñanzas y textos secretos. (SCHNEEMELCHER, 2003, p. 13-14). Otro ejemplo interesante es el artículo de Jean-Daniel Kaestli, ya que si bien en sus conclusiones el autor afirma que no puede considerarse a la literatura apócrifa goblalmente como literatura de "segundo grado" su estudio analiza los textos apócrifos siempre partiendo de la idea de utilizar los canónicos como un "modelo" que se habría continuado, amputado, resumido u ampliado. (KAESTLI, 2000, p. 288-304).

${ }^{3}$ En el primer volumen dedicado a textos apócrifos tanto en el judaísmo como en el cristianismo James $\mathrm{H}$. Charlesworth and Lee Martin McDonald manifiestan incluso los problemas conceptuales que implica la categorización de los textos: "One of the problems scholars encounter is misleading nomenclature. It is difficult to find appropriate terms to describe such texts and the social phenomena surrounding the shaping and formation of the Bible. Terms like "Bible," "biblical," "non-biblical," "canonical," "non-canonical," "apocryphal," "pseudepigraphical," "deutero-canonical," and "de-canonization" are all anachronistic terms for ancient societies. These terms should not be used in reference to this literatura when describing ancient history and many subsequent centuries. Moreover, such terminology is frequently prejudicial and misrepresents both Early Judaism and earliest Christianity." (CHARLESWORTH; MCDONALD, 2010, p. xi). Misma postura en el segundo volumen (CHARLESWORTH; MCDONALD, 2012, p. 1-8). (FINKELBERG; STROUMSA, 2003, p. 1-8).
} 
relacionan, en algunos casos más íntimamente que en otros, tanto con el Judaísmo como con el Cristianismo. Sin embargo, numerosas posturas académicas persisten en un intento de diferenciar de manera defintiva fuentes judías de fuentes cristianas:

\begin{abstract}
"Esta bifuercación se ha naturalizado no solo por sus resonancias sobre las distinciones conducidas por comunidades religiosas contemporámeias, sino también por una distinción similar en las disciplinas académicas. Etiquetar un texto antiguo como "Judío" o "Cristiano" no es solo categorizarlo, en realidad, en la práctica es también delinear los campos dentro de los cuales es (y no es) estudiado". (REED, 2015, p. 137).
\end{abstract}

Para ilustrar nuestro argumento, expondremos la postura de Simon C. Mimouni, celebre estudioso francés de los orígenes del Cristianismo. En su introducción al análisis de "lo apócrifo" en el Cristianismo antiguo y medieval, el autor define el concepto central de su estudio en base a la dependencia del "lo apócrifo" en relación con "lo canónico": "El concepto de apócrifo supone el concepto de canónico [...] es el producto de otro concepto, el de canon" (MIMOUNI, 2002, p. 1)4. Si bien el autor explica que no debe generalizarse dicha oposición, dado que los conceptos de "apócrifo" y "canónico" provienen dos criterios originados en dos medios diferentes (judío en el caso del primero y griego en el caso del segundo), y realiza una exposición histórica de la evolución del término, la postura epistemológica es de unir ambos conceptos de manera directa, definiendo "lo apócrifo" por su negación, como exterior a lo "canónico".

Observamos, entonces, que a pesar de las reservas, se insiste sobre los equívocos que hemos mencionado, pues se parte de una postura que podríamos calificar de heresiólogica ya que se considera "apócrifo" todo aquello que esté fuera de un supuesto canon. Por una parte, ello implica continuar con una visión tradicional sobre dichos textos, que entraña aceptar una división, en algunos casos fundamentada históricamente, pero siempre artificial, entre textos que deben ser incluídos y otros que ameritan ser excluídos. Por otra parte, es necesario preguntarse si las comunidades que dieron origen a estos escritos lo hicieron con la

\footnotetext{
${ }^{4}$ En nota 1 agrega: "Les écrits apocryphes dont il est question ici sont ceux qui sont en dehors de tout canon". (MIMOUNI, 2002, p. 1).
} 
intención de construir un "canon" de textos doctrinales, sagrados e innamovibles o bien tenían una postura más abierta que permitía considerar como fuentes posibles, aún para criticarlas, fuentes de posiciones doctrinales diferentes.

Es en este sentido que consideramos indispensable, intentar un análisis desde los estudios cognitivos y particularmente desde el historicismo cognitivo. Tal como lo expone Lisa Zunshine se trata de un enfoque histórico que toma en cuenta los procesos cognitivos y los procesos sociales en la creación e interpretación de las producciones culturales. Debido a que sólo podemos estudiar las representaciones sociales, creencias y prácticas religiosas tal como son reflejadas en la cultura, este enfoque trata de explicar las relaciones sociales y religiosas a la vez que permite construir el proceso histórico y cognitivo que las origina estudiando las producciones culturales que dejan atrás, ya sean expresiones rituales o libros escritos, gestos prescritos u objetos especiales, diagramas esotéricos o edificios (Zunshine).

En el campo particular de los estudios sobre gnosticismo seguiremos la postura metodológica de April DeConick:

El historicismo cognitivo, es un enfoque crítico y pragmático de las producciones culturales que busca entenderlos y analizarlos como conductos públicos de conectividad mental compartido por los individuos. La interpretación de la producción cultural se ubica en el centro de este enfoque. La producción cultural es entendida como integrada dentro de los sistemas dinámicos de significado-conectividad o redes de conocimiento tanto a escala personal como social. (DECONICK).

Asi, producciones tales como expresiones rituales o textos religiosos, se entienden como representaciones públicas de representaciones mentales individuales, es decir, la exteriorización de ideas, creencias, intenciones y preferencias de una persona. Dichas representaciones son la manifestación y exteriorización de la cognición.

El historicismo cognitivo, entiende que una producción, su arquitecto y sus usuarios, existen dentro de complejas redes de conocimiento y matrices o entornos sociales. Estas redes de conocimiento no existen ontológicamente, aparte de las mentes de los individuos que las crean, las comparten y las habitan a través de expresiones y gestos, o las distribuyen a través de la producción de artefactos físicos. En el nivel más general, 
estas redes de conocimiento son los entramados de relaciones causales que existen entre las representaciones mentales alojadas en la mente de un individuo y compartidas públicamente con las mentes de otras personas que habitan en los grupos o matrices sociales. La representación pública toma la forma de cualquier producción física, incluyendo señales, gestos, rituales, expresiones, textos e imágenes. (SPOSKY, 2003, p. 171172).

Es indispensable, entonces, considerar estos textos dentro de las estructuras mentales de los individuos que les dieron origen para comprender las representaciones existentes en los individuos y compartidas públicamente con las representaciones de otros habitantes de la comunidad. Es decir, analizar estos textos tal cual funcionaban en las sociedades que los crearon. 5 Es por ello que nos parece indispensable estudiar el concepto de "lo apócrifo" en los textos gnósticos partiendo de su acepción original de "oculto" o "secreto" para revalorizarlos en acuerdo con la concepción con la cual fueron escritos ${ }^{6}$.

En el presente trabajo abordaremos la noción de "apócrifo" en un sentido amplio que abarca tanto la noción original existente ya en la literatura antigua de “oculto" como la noción surgida posteriormente de "extracanónico", pero centrando nuestro análisis en la primera ya que dicho cambio se dio aplicando el término peyorativamente a escritos o doctrinas que se quería condenar.7

\section{Breve análisis histórico de las variaciones semánticas}

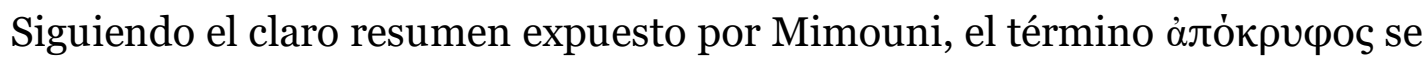

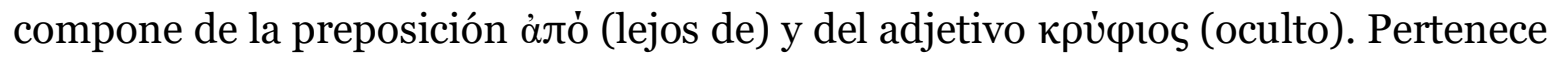
a la lengua griega clásica y ya encontramos el término en Heródoto (Historias II, 35), Eurípides (Heracles 1070) y Xenofón (Banquete VIII, 11) donde se presenta con el significado de "secreto". Grupos religiosos o filosóficos han llamado а̇локрича a libros secretos que contienen una doctrina esotérica. Más tarde, en el

\footnotetext{
${ }^{5}$ Algunos de los autores mencionados previamente han indicado la necesidad de realizar una aproximación similar sobre el tema. Sin embargo, exponen tal necesidad partiendo siempre de una postura que define "lo apócrifo" en relación con "lo canónico". (MIMOUNI, 2002 p. 2); (FINKELBERG; STROUMSA, 2003, p. 1) y (CHARLESWORTH; MCDONALD, 2010, p. x); entre otros.

${ }^{6}$ Incluso una definición amplia como la propuesta por Pierluigi Piovanelli no tiene en cuenta este aspecto central de, al menos una parte, de la literatura llamada "apócrifa". El autor considera los textos apócrifos como "[...] as a "remythologization" of the Christian origins". (PIOVANELLI, 2005, p. 39).

${ }^{7}$ Ver lo expuesto por Bertrand (2002, p. 131).
} 
mundo cristiano, el término designa a los escritos de origen desconocido o aquellos que si bien trataban temas análogos al Nuevo Testamento, no han sido admitidos en el canon. Ambas consideraciones han permitido el pasaje hacia el calificativo de sospechoso e incluso herético (MIMOUNI, 2002, p. 13).

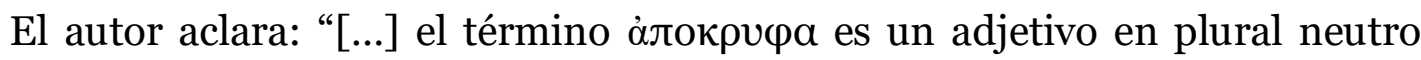
cuyo significado primitivo es el de "cosas ocultas"/ "cosas secretas" o, más precisamente, dado el objeto al cual es aplicado "libros ocultos"/ "libros secretos"” (MIMOUNI, 2002, p. 13). La historia del termino en el judaísmo, indica que la orden de "guardar secretas" las palabras de un libro se encuentra en textos apocalípticos de los siglos II y I a.C. El término "oculto" aplicado a los libros no tiene sentido peyorativo en el judaísmo rabínico, donde se habla de "libros exteriores" para designar tanto los libros "exteriores" a la Ley escrita (TJ Sanhedrin X 28), pero también en referencia a los libros heréticos (TB Sanhedrin 10ob) (MIMOUNI, 2002, p. 14-15).

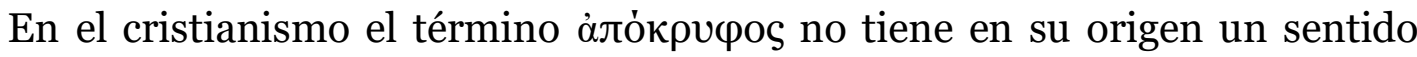
peyerativo, sino que adquirirá dicha consideración a través de ciertos autores, comenzando con Ireneo y Tertuliano en el siglo II, quienes lo asociarán al término vóӨos, concepto técnico de la crítica textual alejandrina para designar escritos "bastardos" es decir de "paternidad ilegítima" (MIMOUNI, 2002, p. 15). Entonces un texto denominado como "apócrifo" puede designar tanto una obra de acceso restringido o una obra ilegítima, corrompida o inauténtica. El autor agrega: "Conviene aclarar que el uso técnico de la palabra "apócrifo" para significar los libros no incluídos en el canon es relativamente tardía: aparentemente no es anterior a Jerónimo" (mediados siglo IV). (MIMOUNI, 2002, p. 16)8 .

\footnotetext{
${ }^{8}$ Por otra parte el autor remarca que el concepto de "apócrifo" no era el mismo en las iglesias consideradas como "centrales" y las de regiones que pueden ser consideradas como "periféricas", orientales y occidentales. (MIMOUNI, 2002, p. 18-19).
} 


\title{
2 La postura de los padres de la Iglesia
}

Tal cual lo hemos visto, el sentido negativo del término apócrifo aparecerá hacia finales del siglo II en los escritos de Ireneo, obispo de Lyon. Sin embargo, podemos observar desde décadas antes con Justino de Roma, denuncias elevadas contra textos elaborados por comunidades doctrinales opuestas. En este apartado, y dado el espacio dedicado a nuestro artículo, expondremos la postura de tres padres de la Iglesia cuyas afirmaciones permitirán encuadrar mejor nuestro trabajo.

En su Diálogo con Trifón, hacia mediados del siglo II, Justino denuncia que los gnósticos se presentan en nombre de Jesus:

\begin{abstract}
y son por nosotros llamados con el sobrenombre del hombre que dio origen a cada doctrina y a cada sistema [...] atribuyen el nombre de Dios a

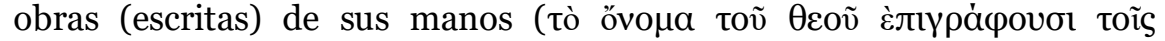
хєіролойтоı) [...] Entre ellos, unos se llaman marcionitas, otros valentinianos, otros basilidianos, otros saturnilianos y otros por otros nombres, llevando cada uno el nombre del fundador de la secta”. (Dial. 35, 4-6. BOBICHON, 2003, p. 270-271)9.
\end{abstract}

En 82,3, 3 retoma el tema de la autoría de las doctrinas enseñadas por estos maestros: "Porque muchos son los que han enseñado, marcándolas con el sello de

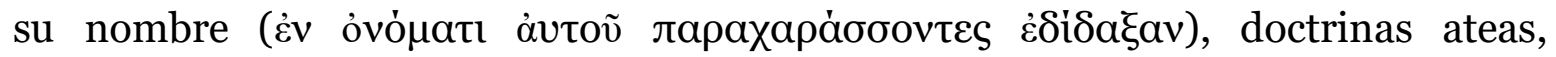
blasfemas e inicuas, y lo que el espíritu impuro, el diablo, arrojó en sus espíritus, eso han enseñado y siguen enseñando" (BOBICHON, 2003, p. 410-411).

Sobre la sabiduría oculta en los textos y sus posibles interpretaciones, Justino reprocha a Trifón (y al judaísmo) la falta de dicernimiento al negar el anuncio de Cristo en las Escrituras: “[...] por su iniquidad, les ocultó Dios la sabiduría contenida en sus palabras (2 Co 3,14-15), a excepción de algunos, a los que por la gracia de su gran misericordia (St 5,11?) dejó, como dijo Isaías, como semilla para la salvación (Is 1,9; 10,22; Rm 9,27. 29)” (Dial. 55, 3. BOBICHON, 2003, p. 322-323). En este sentido dice Bobichon sobre las posibilidades de la

\footnotetext{
${ }^{9}$ Alain Le Boulluec explica: “L'instrument de la critique est fourni par le mode de désignation des écoles, qui renvoie à des hommes et non au Christ". (LE BOULLUEC, 1985, p. 61).
} 
exégesis: "En realidad, si Justino puede presentar y después comentar un mismo texto según perspectivas diferentes, es precisamente, una vez más, porque este texto es, para él, suceptible de varias interpretaciones, porque el asocia versículos portadores de multiples verdades.” (BOBICHON, 2003, p. 120).

En Ireneo, ferviente polemista antignóstico, encontramos ya claramente la condena de los textos concebidos en los círculos valentinanos. En su obra Contra las Herejźas I, 20, 1 (hacia el 177 d.C.) refiriéndose a Marcos el Mago, considerado como discípulo de Valentin, ${ }^{10}$ el obispo de Lyon deja en claro su pensamiento sobre dichos textos: "Además de éstos, ellos han añadido una multitud de escritos

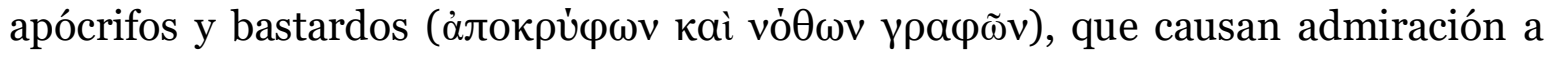
los necios, que desconocen las verdaderas Escrituras"11.

Ireneo califica los textos gnósticos como apócrifos y bastardos, es decir de paternidad dudosa y por lo tanto ilegítimos. Ahora la pregunta es si el calificativo "apócrifo" indica que se trata de textos secretos o más bien ya conlleva una visión negativa o peyorativa. De todas formas ambas posturas no son excluyentes para el obispo, pues el que dichos escritos sean "secretos" fundamenta la sospecha de su propio origen desconocido. En efecto, en 20, 3 Ireneo manifesta que los valentinianos interpretan Mateo 11, 25-27 afirmando poseer secretos ocultos solo a ellos revelados:

"Como culminación de sus pruebas acerca de lo dicho, ellos aportan estas palabras: «Te confieso, Padre, Señor de la tierra y del cielo, porque has escondido estas cosas a los entendidos y prudentes y las has revelado a los pequeños. Gracias, Padre, porque esto te agradó. Todo me lo ha entregado el Padre, y nadie conoce al Padre sino el Hijo, ni al Hijo sino el Padre, y aquél a quien el Hijo se lo revelare» (Mt 11,25-27). Dicen que con estas palabras de modo evidente el Señor habría revelado que, antes de su venida, nadie había conocido al Padre de la Verdad; y de ahí deducirían que todos habrían conocido siempre al Creador y Hacedor; en cambio sus palabras anunciarían al Padre desconocido para todos". (ROUSSEAU; DOUTRELEAU, 1979, p. 292-293).

\footnotetext{
10 Sobre las filiaciones entre Maestros y discípulos gnósticos ver I, 13, 1 y el comentario de los editores (ROUSSEAU; DOUTRELEAU, 1979, p. 240).

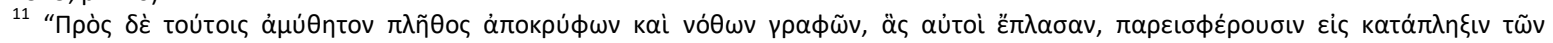

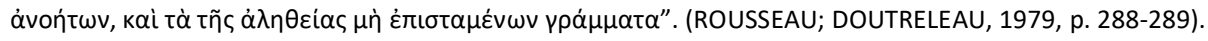


Avanzaremos un poco sobre lo que desarrollaremos más adelante diciendo que el conocimiento que los valentinianos mencionan en este pasaje de Mateo, es la indispensable intermediación del Hijo-Nombre-Intelecto para acceder al conocimiento del Padre-Uno-Todo. Exégesis que por otra parte no es ajena a Ireneo mismo ${ }^{12}$.

Lo expuesto más arriba sobre la posibilidad que Ireneo condene efectivamente lo oculto de las doctrinas valentinianas es afirmado por el prologo 2 del libro III: "Mi querido hermano, me pediste que abiertamente expusiera las

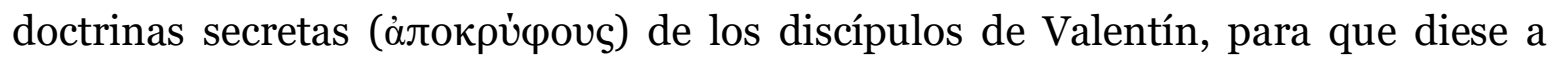
conocer sus muchas facetas, y que al mismo tiempo te ofreciera los argumentos para derrocarlas". (Adv Haer III, Pr. 2. ROUSSEAU; DOUTRELEAU, 2002, p. 1617).

Este conocimiento secreto sólo a ellos revelado, les insta, según el lyonés, a oponerse a la Tradicion:

"Cuando nosotros los atacamos con la Tradición que la Iglesia custodia a partir de los Apóstoles por la sucesión de los presbíteros, se ponen contra la Tradición diciendo que tienen no sólo presbíteros sino también apóstoles más sabios que han encontrado la verdad sincera: porque los Apóstoles «habrían mezclado lo que pertenece a la Ley con las palabras del Salvador»; y no solamente los Apóstoles, sino «el mismo Señor habría predicado cosas que provenían a veces del Demiurgo, a veces del Intermediario, a veces de la Suma Potencia»; en cambio ellos conocerían

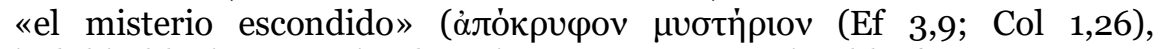
indubitable, incontaminado y sincero: esto no es sino blasfemar contra su Creador. Y terminan por no estar de acuerdo ni con la Tradición ni con las Escrituras.”. (Adv Haer III, 2, 2. ROUSSEAU; DOUTRELEAU, 2002, p. 26-29).

\footnotetext{
${ }^{12}$ Los comentarios de Rosseau y Douletreau confirman la posibilidad de interpretar el versículo del evangelio como el conocimiento del Hijo indispensable para la revelación del Padre y del Hijo, interpretación que si bien no estaba muy difundida en la época pa trística, concuerda con la de Ireneo "Il saute aux yeux que les gnostiques ne pouvaient comprendre que de la seconde manière la phrase citée par eux: pour pouvoir y lire une révélation du Père par le Fils, il leur fallait nécessairement rattacher les mots kai $\tilde{\varphi}$ äv ó Yiòs $\dot{\alpha} \dot{\alpha}_{0 \kappa} \alpha \lambda \dot{\psi} \psi n$ à la totalité de ce qui les précède, ce qui les amenait à concevoir la révélation faite par le Fils comme portant sur le Père et le Fils [...] Quoi qu'il en soit de l'interprétation gnostique, nous savons que cette manière de comprendre le verset évangélique était, sans aucun doute posible, celle d'Irénée [...] Cette manière de comprendre Matth. 11, 27 paraît avoir été plutôt exceptionelle à l'époque patristique car les Pères coupaient plus habituellement le verset en deux membres distincts et comprenaient: "Nul ne connaît le Fils, sinon le Père; nul non plus ne connaît le Père, sinon le Fils et celui à qui le fils voudra révéler (le Père)" (ROUSSEAU; DOUTRELEAU, 1979, p. 267-268). Es interesante que entre los Padres que presentan una interpretacion similar encontramos a Justino en I Apol 63,3 "También Jesucristo mismo, reprendiendo a los judíos por no conocer qué cosa fuera el Padre ni qué el Hijo (Jn 8,19; 16,3), dijo también: "Nadie conoce al Padre, sino el Hijo; ni al Hijo le conoce nadie, sino el Padre y a quienes el Hijo lo revelare" (Mt 11,27). 4. Ahora bien, el Verbo de Dios es Hijo suyo, como antes dijimos (I, 21,1; 22,2; 32,10). 5. Y también se llama Ángel (mensajero) y Apóstol (enviado), porque Él anuncia lo que hay que conocer y es enviado para revelarnos todo lo que está anunciado". (MUNIER, 2006, p. 294-295).
} 
Ireneo responde a lo anterior diciendo que si los apóstoles hubieran conocido "misterios escondidos" los hubieran manifestado a través de la Tradicion por el revindicada. (Adv Haer III, 3, 1. ROUSSEAU; DOUTRELEAU, 2002, p. 3031)13 A continuación para probar la veracidad de sus palabras sobre la Tradicion que comparte con los apóstoles, expone en 3, 3 la lista de los obispos de Roma.

Finalmente proponemos la postura de Clemente de Alejandría quien en Stromata I, 15, 69, 6 hace referencia claramente a "libros secretos" ( $\beta i \beta \lambda$ ovs

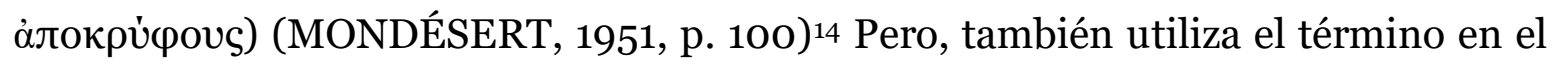
sentido peyorativo que hemos mencionado. En efecto en Stromata III, 4, 29, 1, refiriéndose a la doctrina de los carpocratianos, afirma:

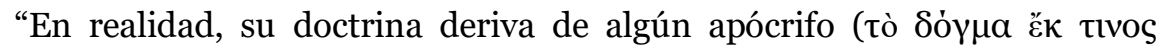
áлокрú(оv); pero también expondré la cita que es la madre de su insolencia. Y bien sea que ellos mismos hayan compuesto el libro -imira qué necedad! Se lo atribuyen a Dios por su intemperancia-, bien sea que lo hayan encontrado junto a otros, lo han entendido de forma incorrecta, equivocándose al idear aquella hermosa doctrina. (MONASTERIO SANTA MARÍA DE LOS TOLDOS, 2015)15.

Encontramos en el alejandrino, ambas acepciones, sin embargo es aún más interesante su postura con respecto a cierto tipo de conocimiento. Para Clemente existe una relación intrínseca entre fe y conocimiento, dónde la primera puede

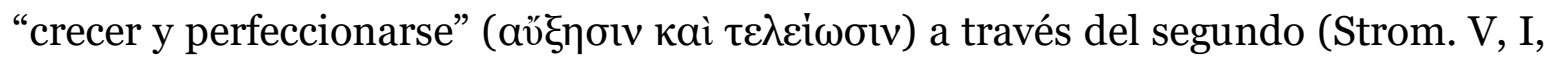
1,1-3 y 2, 4 y 11,1). Así en Stromata $V$ habla de la existencia de una sabiduría oculta que debe enseñarse de manera velada tal cual se ha realizado desde los egipcios y en las diferentes corrientes filosóficas (Strom. V, IV, 21, 4 y VII, 41, 1-IX, 58, 6). Así, los "tesoros ocultos, secretos" a los que hace referencia Isaías 45,3 son una

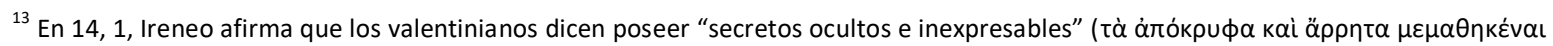
$\mu \cup \sigma \tau$ ń $\mathbf{\alpha}$ ) a lo cual el obispo responde negando los gnósticos, marcionitas y valentinianos puntualmente (III 12, 12), pudieran tener estos de Pablo siendo que Lucas, quien lo acompaño en su predicación no los transmite en su evangelio. (ROUSSEAU; DOUTRELEAU, 2002, p. 262-263).

${ }^{14}$ Daniel Bertrand indica lúcidamente sobre la multiplicidad de significados que el termino apócrifo encerra todavía en los escrito de Clemente de Alejandría: "[...] quand Clément qualifie d'“apocryphes" les livres de Zoroastre que certains gnostiques se vantent de posséder, il ne veut évidement pas dire qu'ils ne sont pas scripturaires, mais seulement qu'ils sont ésotériques, conservant par là au mot son extension primitive." (BERTRAND, 2002, p. 131).

${ }^{15}$ No existe una versión del texto Stromata III en Sources Chretiennes, por lo cual aportamos al lector una traducción y un texto

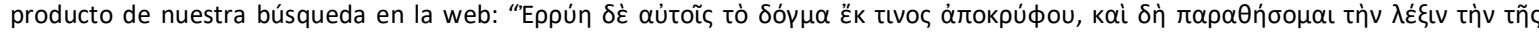

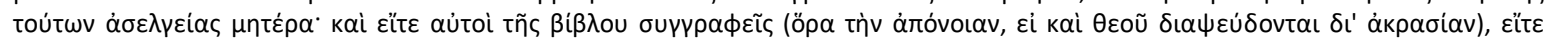

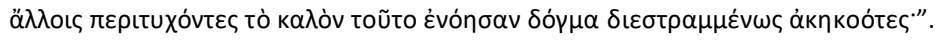


"sabiduría difícil de obtener" (Strom. V, 4, 23, 2. LE BOULLUEC; VOULET, 2006, p. 62-63). ${ }^{16}$ De la misma manera, Clemente observa en las Escrituras la indicación sobre la necesidad de una enseñanza sobre la divinidad a través de dos medios de

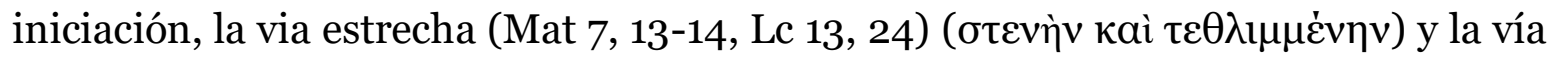

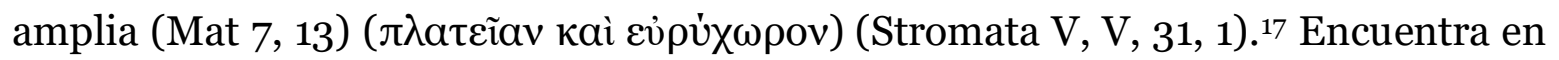

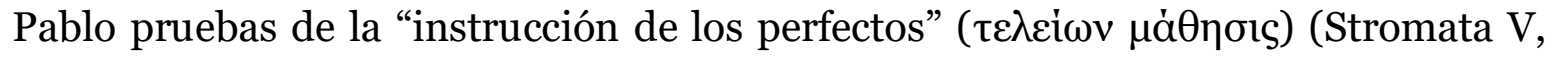
X, 6o, 2. LE BOULLUEC; VOULET, 2006, p. 124-125) sobre los "misterios ocultos

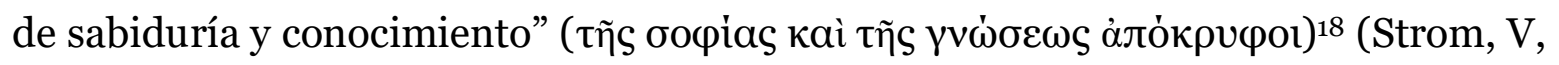
X, 61,4). Clemente afirma: “[...] son los misterios ocultos hasta los Apóstoles y que han sido transmitidos por ellos como los recibieron del Señor -escondidos en el Antiguo Testamento-, los cuales “ahora han sido revelados a los santos” (Col 1,26).” (Strom. V, X, 61, 1. LE BOULLUEC; VOULET, 2006, p. 126-127)19.

Es clara entonces la condena de los Padres de la Iglesia ante los escritos citados por los autores gnósticos. Resulta menos evidente el objeto de su crítica. Lo que se critica es la autoría humana e intracomunitaria de estas obras. En el caso de Ireneo también puede considerarse una oposición a su carácter secreto, además de su origen desconocido. ${ }^{20}$ Lo que se critica entonces, es una postura doctrinal surgida de una forma particular de exégesis basada en una herencia tradicional

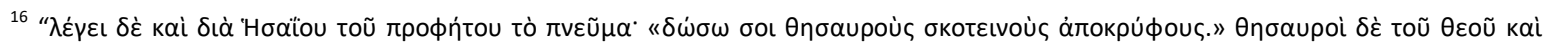

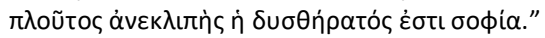

${ }^{17}$ Lamentablemente no podemos citarlos "in extenso" pero los pasajes de Stromata I, 12, 55, 1-56, 2 no dejan lugar a dudas sobre la postura clementina: "Puesto que la tradición no es cosa vulgar y pública, al menos para darse cuenta de la grandeza del Verbo, es

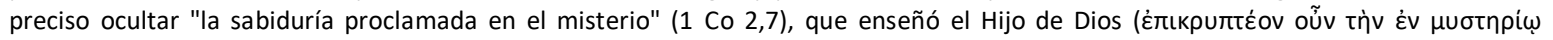

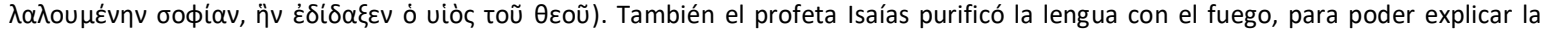
visión (Is 6,1-7); y no solamente la lengua, sino también los oídos debemos purificar nosotros, si pretendemos al menos ser partícipes

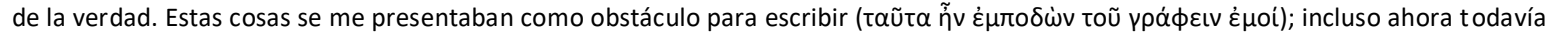
tengo reparos, como dice [la Escritura], "en arrojar las perlas a los cerdos, no sea que las pisoteen con las patas y, volviéndose, los despedacen" (Mt 7,6). Porque en verdad es peligroso decir palabras puras y luminosas acerca de la verdadera luz ante oyentes

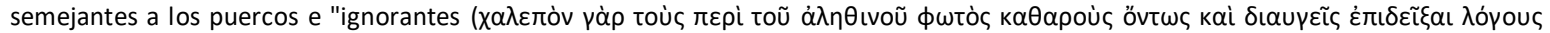

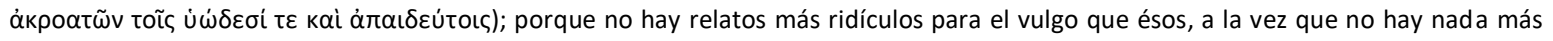
maravilloso y más inspirado para los bien dispuestos". "El hombre psíquico no recibe lo que [viene] del Espíritu de Dios, porque para él es una locura" (1 Co 2,14). "En cambio, los sabios no dejan salir de la boca lo que se habla en el consejo" ( $\operatorname{Pr} 24,7)$. Con todo, dice el Señor: "Lo que oyen al oído, proclámenlo sobre los tejados" (Mt 10,27), exhortando a recibir las tradiciones ocultas de la verdadera

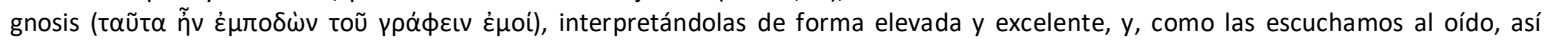
también las hemos de transmitir a quien se deba; pero no las hemos de publicar a todos sin más, explicando lo que a ellos se les ha dicho en parábolas.(MONDÉSERT, 1951, p. 89).

${ }^{18} \mathrm{Col} 2,2-3$. Interpretación retomada sobre la importancia del conocimiento oculto en Strom V, XII, 80, 5

${ }^{19}$ Del mismo modo interpreta nuevamente Is. 45, 3 en Strom V, X, 64, 1.

20 Daniel Bertrand subraya el hecho que Ireneo utiliza poco el concepto, sobre todo dada su intención inicial de denunciar "la pretendida gnosis". El autor recalca el hecho que solo en el primer libro el obispo lyonés expone las doctrinas heréticas mie ntras que los otros cuatro discuten sobre diversos puntos de vista. Para Bertrand esto se debe a que los heresiólogos, tanto Ireneo como Hipólito, no pretenden tanto refutar las doctrinas consideradas heréticas como denunciarlas. (Bertrand, 2002, p. 139).
} 
exclusiva. Herencia exclusiva que es similar a la revindicada por Ireneo como la Tradición verdadera legada de los apóstoles a través de su famoso listado de los obispos romanos. El análisis de la obra de Clemente de Alejandría nos ha permitido clarificar este punto. En efecto el alejandrino acepta la existencia de un conocimiento secreto, solo accesible a los "perfectos" pero niega a los gnósticos (entre ellos los discípulos de Valentín) la posibilidad de poseer dicho conocimiento. Tomando las palabras de Christoph Markschies:

Así que esta línea de argumentación valentiniana fue a primera vista un voto de gran alcance para la tradición oral contra la tradición escrita de la corriente principal de la Iglesia. En otras palabras, no hay una gran diferencia en la teoría hermenéutica en relación con la oralidad y o la literalidad de la escritura entre la corriente principal de la teología y los gnósticos valentinianos. Esta sorprendente similitud llegaría a ser aún más clara cuando se examine la visión de Clemente de Alejandría." (MARKSCHIES, 2003, p. 180-181) ${ }^{21}$.

En efecto en Stromata I, I, 4, 1 y I, 5, 1 Clemente afirma:

Si dos [personas] anuncian la Palabra, una por escrito y otra oralmente, ¿cómo no aprobar a ambas, puesto que por la caridad han hecho operativa la fe (cf. Ga 5,6)? La responsabilidad de no escoger lo mejor es de quien elige; Dios no es culpable (o: no es responsable). De ahí que a unos les corresponda colocar a interés la palabra, y a otros examinarla y elegirla o no; el juicio se juzga en ellos mismos [...] Es necesario, por tanto, que entre ambos nos examinemos a nosotros mismos, el que habla, si es digno de hablar y de dejar memorias escritas, el que escucha, si merece escuchar y leer. Así, quienes reparten la Eucaristía, según es costumbre, también encarecen a cada uno de los asistentes que tomen la porción que les corresponde. (MONDESERT; CASTER, 1951, p. 46-47).

La Tradición a la cual cada uno se adscribe es entonces el problema, en palabras de Alain Le Boulluec: "Vemos que la lucha contra la interpretación herética es inseparable de la controversia en torno a la tradición. La heresiología tiene por finalidad la ruina de la autoridad de la tradición reclamada por los oponentes." (LE BOULLUEC, 1985, p. 249).

\footnotetext{
${ }^{21}$ Que es por otra parte la misma postura de Alain Le Boulluec: “La polémique d'Irénée montre bien que la tradition est l'objet du litige; la riposte tend à le cacher en transformant la quête gnostique en recherche dérisoire et sans fin; cette réplique doit imposer comme seul exégèse possible celle de l'Église, et assimiler entièrement le sens des Écritures à la doctrine reçue dans cette Église, [...] on a affaire à une querelle d'authénticité, à la façon dont chacun des partis conçoit l'autorité des Écritures. Irénée et les siens lui donnent une extension pleine et définitive: arrêtée et parfaite, déterminée par l'union complète entre le contenu canonique des Écritures et la règle de foi. Les gnostiques de leur côté considèrent que la révélation n'est pas finie et qu'elle peut enrichir l'interprétation des Écritures, l'approfondir toujours davantage, selon une recherche inlassable qui est le signe et la condition de l'élection". (LE BOULLUEC, 1985, p. 244-245).
} 


\section{Los escritos gnósticos}

Es entonces la Tradición la que se encuentra en el ojo de la tormenta, y para los autores gnósticos dicha Tradición ha sido revelada por el Salvador y es transmitida a través de escritos "apócrifos", de sabiduría oculta, conteniendo conocimientos secretos.

Dentro del ámplio abanico de los denominados textos gnósticos, el uso de tal acepción del término es evidente en ciertos textos y velado en otros. Partiremos de un elemento aparentemente explícito con el análisis del Libro de los Secretos de Juan (NH II, 1; III, 1; IV, 1 y BG 8502,2), cuya datación se inicia hacia mediados siglo II y finaliza con una revisión armonizadora hacia mediados del siglo III (TORRENTS, 2000, p. 232; TARDIEU, 1984, p. 40-47). El texto tiene una amplia difusión según lo testimonina las cuatro versiones encontradas y en las cuatro presenta su título original "kata iōannēn apokryphon (NHII 32, 8-10) kata iō $[\bar{e}] n$ $n$ apokryphon (NH IV 49, 27-28) p apokryphon $n$ iōhannēs (NH III, 40, 10-11 y BG 77, 6-7). (WALDSTEIN; WISSE, 1995, p. 176-177. BARC, 2007, p. 258) ${ }^{22}$.

Desde el principio del mismo se da cuenta de la naturaleza del escrito: "La enseñanza [del Salvador y la revelación] de los misterios y de las cosas escondidas en el silencio (pqōlp ebol nm mysterion mn nethēp hn oumntkarōf), que él enseñó a Juan, su discípulo” (NH II, 1-4. WALDSTEIN; WISSE, 1995, p. 13).

La necesidad del secreto es remarcada en las palabras finales (ApocJn $\mathrm{NH}$ III, 39, 17; BG 75, 18-19; NH IV, 49, 12 y NH II 31, 29). Seguimos NH II “Te he dicho todas estas cosas para que las escribas y las transmitas secretamente (eknasha sou n ktaau n nekshbr pna hn ouhōp) a los que participan de tu espíritu: este es el misterio de la raza inconmovible (pai gar pe pmystērion ntgenea nat kim) (NH II, 31, 29-37.WALDSTEIN; WISSE, 1995, p. 174-177). El verbo shai tiene el sentido de "escribir”, "registrar”, “dibujar”, “pintar” y también designa la letra

\footnotetext{
${ }^{22}$ Waldstein y Wisse aceptan la traducción de "libro secreto" (1995, p. 231) al igual que Barc (2007, p. 217 y p. 258 y nota 1, 1-4. (BARC, 2007, p. 212). M Tardieu dice: "La bonne leçon est donc celle de B III: l'Évangile transmettait un message exotérique "selon" Jean, I'Apocryphon veut transmettre le message ésotérique, c'est-à-dire authentique, “de" Jean. (TARDIEU, 1984, p. 345).
} 
(alfabética) (CRUM, 1962, p. 381b-382b); está presente en las cuatro versiones. Todas indican también la orden de mantener en secreto lo revelado, si bien son utilizados términos diferentes. En III, 39, 24 (ouasphalia), en II, 31, 30 y IV, 49,12 (ouhōp) y en BG 75,9 outadjro (WALDSTEIN; WISSE, 1995, p. 174-175)23.

“Apócrifo" explica Michel Tardieu, es un término técnico que designa la presentación de una educación de parte de un maestro de revelación para con el discípulo, cuyo contenido son las doctrinas ocultas, es decir, ambos transtemporales y esotéricas. El silencio indica transtemporalidad ya que dichas doctrinas no pertenecen al lenguaje humano sino que provienen de lo indecible (TARDIEU, 1984, p. 240) ${ }^{24}$.

Otro texto, donde aparece explícitamente la noción de "apócrifo" con el sentido de "secreto", es el relato del Martirio de Pedro, única parte de los Hechos de Pedro que se ha conservado en el griego original. Gérard Poupon situa el apócrifo en su forma primitiva en un ambiente griego-siríaco hacia finales del siglo II o principios del siglo III (POUPON, 1997, p. 1043). El autor considera que parte de los capítulos referidos al martirio "[...] provienen de corrientes platonizantes y gnósticas” (POUPON, 1997, p. 1043).

Dice el texto:

Y cuando hubo llegado a la cruz comenzó a decir: 'O nombre de la cruz, Misterio escondido; $\mathrm{O}$ misericordia inefable, que se expresa en el nombre de la cruz; O naturaleza del hombre, que no puede ser separada de Dios; O amor inefable e inseparable, que no se pueden ser manifestados por labios impuros; Te alcanzo ahora, de pie al final de mi carrera terrenal. Voy a dar

\footnotetext{
23 "fortificar, afirmar asegurar" (CRUM, 1962, p. 462b).

${ }^{24}$ M. Tardieu explica: "Même entrant dans le temps para la parole de révélation, ces doctrines resteront ésotériques, c'est-à-dire des mustēria (lat. secreta) transmis exclusivement à une petit groupe d'initiés, compagnons de route du récipiendaire de la révélation. [...] l'élaboration de l'apokruphon en livre à contenu transcendent et caché "silencieusement" est spécifique d'une littérature gnostique se démarquant des livres à contenu historique et public de la Synagoge et de l'Église naissante." (TARDIEU, 1984, p .240). Barc nos explica: "L'auteur (c-à-d. du Livre des secrets de Jean) connaît l'Évangile selon Jean et y fait allusion à plussieurs reprises, de façon souvent polemique, car il ný voit quúne ébauchede révélation imparfaite et incomplète, don't le Livre de secrets vient dévoiler le sens véritable". (BARC, 2007, p. 208).
} 
conocimiento de tí. No voy a ocultar el misterio de la cruz, una vez cerrado y oculto a mi alma. (Acta Petri, Martyrium Petri 37. ELLIOT, 2005, p. 424). 25

Se trata del prologo a un discurso de revelación en el cual Pedro se dirige primero hacia la cruz y luego hacia su auditorio para revelarles las condiciones para acceder al conocimiento del misterio basado en el desapego del mundo sensible. "Apartad vuestras almas de todo lo que puede ser percibido con los sentidos, de todo lo que parece ser, y no es, verdaderamente real. Cerrad estos vuestros ojos, cerrad estos vuestros oídos; retiraos de las acciones que son vistas externamente y percibirán los hechos acerca de Cristo y todo el misterio de vuestra salvación” (ELLIOT, 2005, p. 425) ${ }^{26}$.

El conocimiento secreto transmitido por la cruz es tratado en el apartado 38 , dónde Pedro denuncia que la realidad sensible no es más que una ilusión dónde el hombre es engañado a través de la inversión del orden del mundo. La crucifixión invertida del apóstol denuncia tal estado al tiempo que enuncia el conocimiento salvífico a través de las palabras del Salvador, similares a las existentes en el Evangelio de Tomas (NH II, 2, 22, 23-35) : "Con respecto a esto, el Señor dice en un misterio, "A menos que hagais la derecha como la izquierda y la izquierda como de la derecha, y la parte superior como la parte inferior y la parte delantera como la parte de atrás, no conocereis el Reino (ELLIOT, 2005, p. 425; POUPON, 1997, p. 1110 notas $\mathrm{A} \mathrm{y} \mathrm{H})^{27}$.

El Libro Secreto de Santiago (NH I, 2), texto valentiniano ${ }^{28}$ datado entre mediados del siglo II y principios del siglo III, (ROULEAU, 1987, p. 22; WILLIAMS, 1985, p. 27) ha recibido su título por parte de los editores pues se

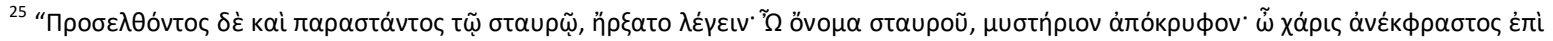

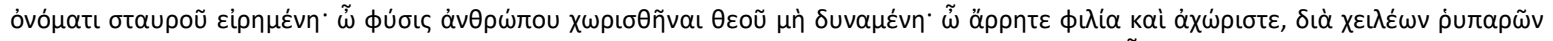

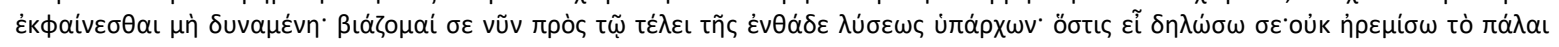

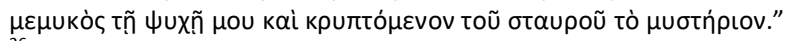

${ }^{26}$ La frase siguiente indica: "Y ahora especialmente, ya que Ustedes pueden escucharlo de mí que estoy en la última hora de la vida, escuchen" (ELLIOT, 2005, p. 425). Gérard Poupon remarca en esta frase la indicación que la iniciación esta reservada a aquellos dispuestos a recibirla (POUPON, 1997, p. 1110 note f). Lo afirmado está sustentado por una clausula secreta, solo presente en el manuscrito de Patmos, que indica la necesidad de mantener oculto dicho conocimiento "Et que tout ce qui vous aura été dit, à vous qui l'entendez, soit comme s'il ne l'avait pas été". (POUPON, 1997, p. 1110 y nota H).

${ }^{27}$ Sobre el Evangelio de Tomas ver: Sevrin (2007, p. 314).

${ }^{28}$ Sobre valentinismo del texto ver: Williams (1985, p. 18-27) y ver también: Rouleau (2007, p. 17).
} 
presenta a sí mismo como un "escrito secreto" en el cual Jesus tras la resurrección revela a Santiago y Pedro el conocimiento que luego Santiago pone por escrito: “Te envié un escrito que me fue revelado junto con Pedro por el Señor (atratnnau nek nouapokrypho(n) eauqalp $<f>$ aval nnēei ntstak petros hitm pdjais)" (ApocSant I, 9-10. WILLIAMS, 1985, p. 28-29). Se indica la naturaleza del texto, una tradición recibida secretamente, un conocimiento esotérico, revelación recibida luego de la resurrección y escrita en hebreo "lo [he escrito] en caracteres hebreos" (ApocSant I, 16. WILLIAMS, 1985, p. 28-29). A continuación el autor menciona que ha escrito, al menos, otro texto de la misma índole “Además te he enviado hace diez meses otro escrito secreto que me reveló el Salvador (nkeapokryphon eaufqalpf nhi aval nqi psōtēr)" (ApocSant I, 29-30. WILLIAMS, 1985, p. 28-29). Finalmente, se destaca la importancia de mantener el secreto sobre lo comunicado “[...] ten cuidado en no divulgar este escrito a muchos, el que el Señor no quiso comunicar a todos nosotros, sus doce discípulos” (Apoc Sant I, 20-25. WILLIAMS, 1985, p. 2829) 29 .

Sobre la comunidad gnóstica cristiana que se encuentra detrás de este texto, Francisco García Bazán nos dice que fundamenta su conocimiento en la revelación relizada por

la naturaleza pneumática del salvador y no la simple proximidad histórica. La tesis entra en fricción con la formulación del concepto eclesiástico de tradición, basada en la Escritura, la profecía y la tradición apostólica, y abona la tradición secreta basada en la sucesión de los elegidos, que es el marco obligado de la exégesis espiritual. (BAZAN, 1999, p. 294).

Es evidente, entonces que los textos expresados dicen transmitir un “misterio secreto", pero ¿en qué consiste dicho conocimiento? ¿En qué consisten las representaciones mentales del o los autores y de la comunidad de la cual forman parte, que conllevan a designar un texto como "apócrifo”? ¿Cuál es el secreto revelado? Una pista notable nos entrega el Evangelio de la Verdad,30 texto valentiniano temprano que puede datarse hacia mediados del siglo II (BAZÁN,

\footnotetext{
${ }^{29}$ Ver también: Williams (1985, p. 16-17).

${ }^{30}$ Ireneo conoce la existencia de un texto llamado Evangelio de la Verdad pero no se trata del mismo escrito. Adv Haer III, 11, 9 (ROUSSEAU; DOUTRELEAU, 2002, p. 172-175). Ver también: Le Boulluec (1985, p. 229).
} 
1999, p. 141; PASQUIER; THOMASSEN, 2007, p. 46 y 52). ${ }^{31}$ Desde sus primeras palabras el escrito anuncia:

El evangelio de la verdad ( $p$ euangelion ntmēe) es alegría para quienes han recibido de parte del Padre de la verdad el don de conocerlo por el poder de la Palabra que ha venido desde el Pleroma (hn tqam mpishedje ntahi ebal hn piplērōma), la que está en el Pensamiento y el Intelecto del Padre, la que es llamada el Salvador, ya que es el nombre de la obra que debe llevar a cabo para la salvación de quienes eran ignorantes del Padre, pero el evangelio es la manifestación de la esperanza que se descubre por quienes le buscan (dje [m]peyangelion pe pouōnh aval nte tihelpis epqine pe nneei etkōte nsōf). (EvV 16,31-17,4. ATTRIDGE; MACRAE, 1985, p. 82$83)^{32}$.

El evangelio entonces, participa de la Palabra que anuncia al Padre, es la manifestación de dicho conocimiento:

[...] cuando el Padre sea conocido, el olvido a partir de ese momento dejará de existir. Este es el evangelio del que se busca (peei peuangelion mpetoukōte nsōf ntafouanhf nnetdjēk aval), que se reveló a los que son perfectos por las misericordias del Padre, el misterio oculto, Jesus, el Cristo (pimystērion ethēp iēe(sou)s peksr(isto)s), por cuyo medio iluminó a los que estaban en la oscuridad a causa del olvido. (EvV 18, 9-17. ATTRIDGE; MACRAE, 1985, p. 84-85. BAZÁN, 1999, p. 147).

El evangelio anuncia que el Jesus histórico es el camino hacia el conocimiento de su Padre. El Salvador enviado por el Pleroma como la Palabra manifestada desde el Intellecto del Padre. La revelación paterna, entonces, solo es posible a través del Hijo (BAZÁN, 2011, p. 103-250).33 El texto plantea una asimiliacion entre la predicación y manifestación del Hijo en tanto que Jesus histórico y el "Libro viviente del Viviente" (pidjōōme etanh nte netanh) (EvV 19,35. ATTRIDGE; MACRAE, 1985, p. 86-87). El libro comprende la revelación del pensamiento del Padre, oculto hasta la manifestación del Hijo y solo posible para los iniciados a través de la predicación de Jesus. Contiene a totalidad de los nombres de aquellos destinados a la salvación pero es principalmente, la revelación

\footnotetext{
${ }^{31}$ Harold W. Attridge and George W. MacRae afirman: "that its a "exoteric work" "directed at the general membership of the Church in such communities (esto es, valentinian) as Rome or Alexandria" (ATTRIDGE; MACRAE, 1985, p. 80).

${ }^{32}$ García Bazán en (1999, p. 146), expone "[...] ante una audiencia reservada el sentido y contenido implícito del "evangelio", en tendido como la proclamación del misterio oculto, Jesus, en tanto que revela al Cristo pleromático y cumple así la obra de salvación en la intimidad del gnóstico" (BAZÁN, 1999, p. 141) y "la profundidad de la reflexión y el vuelo misteriosófico del escrito" (BAZÁN, 1999, p. 144) Cf. Pasquier-Thomassen, 2007, p. 47 y 51. Es de destacar que García Bazán subraya el orden de los escritos del codex I, donde el evangelio de la verdad es precedido por el “Apocrifo de Santiago NH I, 2". (García Bazán, 1999, p. 141).

${ }^{33}$ Ver también: Troiano (2017).
} 
del Intelecto paterno donde todo lo que existe ha sido concebido (Timeo 30c-31b). El texto es explicito al respecto: “(el libro viviente del Viviente) escrito en el Pensamiento y el Intelecto del Padre (peei etsēh hrēei hm pimeeue ouahm pinous nte piōt), y que desde antes del establecimiento de la Totalidad estaba en su Incomprensibilidad” (EvV 19, 35-20, 4. ATTRIDGE; MACRAE, 1985, p. 86-87).

La calidad esotérica del libro abarca su escritura:

Éste es el conocimiento del libro viviente que reveló a los eones, por fin, como [sus le]tras, revelando cómo no son vocales ni consonantes, (eiō[e]dje ehn topos en ne nte hncmē oude hn sheei en ne), para que el que las lea piense en algo vano, sino que son letras de la Verdad que sólo pronuncian los que las conocen. Cada letra es un pen[samiento] completo, como un libro completo, porque son letras escritas por la Unidad, habiéndolas escrito el Padre, para que los eones por medio de sus letras conozcan al Padre". (hitootou nnisheei ntootof euasouōn piōt)". (Ev Ver 22, 36-23,19. ATTRIDGE; MACRAE, 1985, p. 90-91).

Los términos coptos smē y sheei (vb shai) hacen referencia el primero a la vibración sonora, la voz (CRUM, 1962, p. 354b) y el segundo significa "escribir, dibujar, pintar" (CRUM, 1962, p. 381b), lo cual indica que la lengua divina en la cual esta escrito el Libro Viviente del Viviente, es imposible de pronunciar o de escribir.

Entonces, el Hijo es la Palabra, manifestación del Padre y libro viviente, manifestación del Intelecto paterno donde todo pre-existe. Por lo tanto, podemos inferir que el Evangelio de la Verdad es un anuncio, una especie de reseña o si se prefiere de traducción en lenguaje humano de dicha obra. "Ésta es la Palabra del evangelio del descubrimiento del Pleroma ( $p e<e i>$ pe plogos mpishmnoufe ntqine nte piplèrōma), para los que esperan la salvación que viene de lo alto" (Ev Ver 34,36-35,1. ATTRIDGE; MACRAE, 1985, p. 106-107).34

\footnotetext{
${ }^{34}$ EvV sobre la palabra proferida y la palabra oculta en $36,36-38,5$.
} 
Jesus de Nazaret es el Hijo, el Verbo y el Nombre del Padre, la primera emanación que manifiesta al Padre (Pasquier-Thomassen, 2007, p. 47).35 "Por consiguiente, cuando le ha parecido bien que su nombre amado sea su Hijo (ntare[ff]fōk qe efnhētf dje pefren etouashf pefshēre pe), le dio el nombre a él, este que salió de la profundidad, expresó sus realidades secretas (anefpethēp),36 sabiendo que el Padre es carente de mal”. (EvV 40, 23-30. ATTRIDGE; MACRAE, 1985, p. 114-115; BAZÁN, 1999, p. 159-160).

Por último, el Evangelio de Felipe (NH II, 3) texto valentiniano datado entre mediados del siglo II y principios del siglo III (RUBIO, 1999, p. 20; ISENBERG, 1989, p. 134-135), nos indica algo más sobre las formas que toma la revelación: "La verdad no vino al mundo desnuda, sino que vino en símbolos e imágenes; (el mundo), de otra forma, no podría recibirla. (talētheia mpecei epkosmos eskakahēu alla ntasei hn ntoupos mn nhikōn fnadjits an nkerēte)" (Ev Flp 67, 9-11. ISENBERG, 1989, p. 174-175)37.

La verdad no puede ser revelda directamente, sino que debe ser anunciada “oculta” por símbolos e imágenes. Sobre lo oculto y su interpretación en base a los evangelios citamos in extenso el evangelio:

El Señor hizo todo en un misterio (apdjoei[s r]hōb nim hēènou mystērion), un bautismo, una unción, una eucaristía una redención y una cámara nupcial. [...] dijo: "Yo he venido a hacer [lo que está abajo] como lo que está [arriba y lo] que está fuera como lo que [está dentro, a fin de reunirlos] en el lugar" [...] aquí mediante tipos [e imágenes]. Los que dicen que hay un hombre celestial y uno por encima de él yerran, pues el que se revela es aquel hombre celestial al que ellos denominan "el que está abajo", y aquel de quien es lo que está oculto es el que se halla por encima de él. Pues mejor sería decir: "Lo interior y lo exterior, y lo que se halla fuera de lo exterior". Por ello el Señor denominó a la destrucción "la

\footnotetext{
${ }^{35}$ Sobre el desarrollo de la imagen del nombre el texto se extiende (EvV 38,5-41,3) pero queremos subrayar el hecho que el hijo en tanto que libro, Verbo, Hijo y nombre es la revelación de los secretos del padre: “El nombre del Padre, empero, es el Hijo [...] Suyo es el nombre, suyo es el Hijo. Es posible para éste verlo. Pero el nombre es invisible porque sólo él es el secreto del Invisible [...] Porque, realmente, el nombre del Padre no es dicho, sino que ser revela por medio del Hijo". EvV 38,6-24 (ATTRIDGE; MACRAE, 1985, p. 110111).

${ }^{36}$ El verbo se encuentra bajo 2] (CRUM, 1962, p. 695a) se traduce como "estar oculto", "oculto" y transmite el griego $\lambda \alpha v \theta a v \varepsilon i v$,

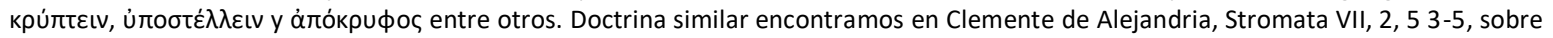

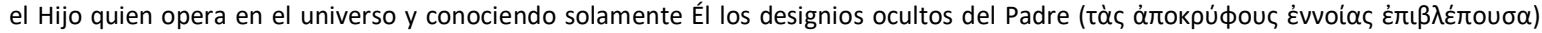
(LE BOULLUEC, 1997, p. 48-49).

${ }^{37}$ Fernando Bermejo Rubio comenta a propósito de este párrafo lo siguiente "Esta necesidad de la mediación explica la importancia que nuestro texto otorga a los sacramentos: por débil y despreciables que sean en comparación con la Verdad, las imágenes y los símbolos son indispensables para llegar a ésta" (RUBIO, 1999, p. 38, nota 101).
} 
tiniebla exterior"; no hay nada fuera de ella. Él dijo: "Mi Padre que está en lo oculto" (Mt 6,6) (paeiōt ethm pethēp). El dijo: "Entra en tu habitación, cierra la puerta tras de ti y ora a tu Padre que está en lo oculto", es decir "El que está en el interior de todos ellos. (EvFlp 67, 29-68, 15. RUBIO, 1999, p. 38-39; ISENBERG, 1989, p. 176-177).

Es este, entonces, el conocimiento secreto transmitido por los autores valentinianos a través de sus textos apócrifos.

\section{Conclusion}

El objetivo principal de nuestro trabajo ha sido el de tratar de exponer una postura diferente en el análisis de textos denominados "apócrifos". Sin negar las variaciones históricas de sentido ni las críticas particulares elevadas por los heresiólogos y Padre de la Iglesia hemos querido retomar el sentido original del concepto.

En este sentido, la existencia de libros secretos y de un conocimiento oculto es por un lado aceptada y criticada por los Padres que rechazan dichos escritos por considerarlos vehículos de un saber opuesto a la doctrina por ellos profesada. Por otro lado, algunos revindicarán la necesidad de una iniciación en "lo oculto" al elaborar su propia doctrina sobre el contenido y el acceso al conocimiento secreto. Es así como se revela que el conflicto subyacente a esta polémica es la defensa del significado antropológico, cosmológico y escatológico transmitido por una determinada Tradición y la manera de sustentar su legado. Tal como lo afirma M. Tardieu: "La exégesis neotestamentaria es la heredera directa de la exégesis judía y punto de pasaje hacia los gnósticos" (TARDIEU, 1984, p. 9).

Llegado a este punto, hemos mostrado que el concepto de "apócrifo" enunciado por y en los textos gnósticos, principalmente, valentinianos; remite a la descripción de la naturaleza misma del escrito. El autor del Evangelio de la Verdad, está transmitiendo en un lenguaje simbólico un texto que contiene la llave para acceder al libro que compendia todo lo existente, al conocimiento último. El uso particular del termino estudiado responde, entonces, a la particular representación que dichos autores tenían de su universo y del lugar que ocupaban 
en él. En palabras de Simon Mimouni (los “apócrifos” transmiten "las creencias de las primeras comunidades cristianas, y sobre todo, sobre el imaginario, vehículo de creación y reflexión” (MIMOUNI, 2002, p. 20).

No pretendemos que el presente abordaje sea aplicado a todos los textos considerados como "apócrifos", pero pensamos que la investigación científica no puede desdeñar los aportes realizados por estas fuentes y continuar con una mirada heresiológica que las considera aún "apócrifas”; en el sentido moderno del término como una mala copia de un modelo "canónico". Considerados tanto por rabinos como por eclesiásticos como "fuera del canon" y por lo tanto no determinantes para la historia y la teología, los textos “apócrifos” se han revelado como indispensables para la comprensión no sólo de la formación de dicho canon, sino también como depósitos de sucesos, conceptos e ideas que alguna vez pertenecieron a determinados grupos tanto judíos como cristianos y que fueron luego dejados de lado en el intento de establecer un conjunto cerrado de textos con el fin de establecer cierta “autoridad”. ${ }^{38}$ Es necesario retomar estos escritos desde la visión original de sus autores y descubrir el secreto que quieren comunicarnos, que en el caso de los textos aquí analizados no es otro que el expuesto por los Extractos de Teodoto 78, 2: “¿Quienes eramos? ¿Que hemos devenido? ¿Dónde estábamos? ¿Dónde hemos sido arrojados? ¿Hacia dónde nos dirigimos? ¿De qué hemos sido redimidos? ¿Qué es la generación? ¿Y la regeneración? (SAGNARD, 1970, p. 202$203)^{39}$.

\footnotetext{
${ }^{38}$ La importancia de estos textos se destaca sobre todo si tenemos en cuenta, tal cual lo expone Christoph Markschies, la necesidad de usar modelos para describir las formación del canon del Nuevo Testamento sobre todo dada la escases de textos que han llegado hasta nosotros. (MARKSCHIES, 2003, p. 175). Ver también Pierre Gisel, citado por Simon C. Mimouni, quien amplia y fundamenta la necesidad del estudio de los textos llamados apócrifos. (MIMOUNI, 2002, pp. 6 y 7). Sin embargo, dichos autores parten siempre de la oposición que hemos denunciado: "apócrifo" vs "canon".

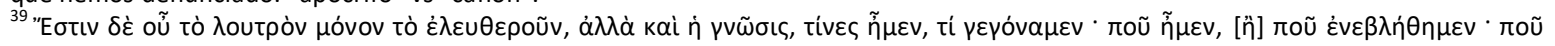

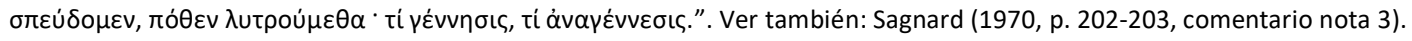




\section{REFERENCIAS}

ATTRIDGE, H.W.; MACRAE, G.W. The gospel of truth. In: ATTRIDGE, H.W. Nag Hammadi codex i (the Jung codex). (NHS XXII). Leiden: Brill, 1985. p. 5-122.

BARC, B. Livre des secrets de Jean (NH II, I; III, I; IV, I; BG 2). Translated by Bernard Barc. In: MAHE, J.-P-; POIRIER, P.-H. (Dir.). Écrits gnostiques. Paris: Gallimard, 2007. p. 205-295.

BAZÁN, Francisco García. Apócrifo de Santiago NHC I 2. In: PIÑERO, A. et al (Ed.). Traducido por Francisco García Bazán. Textos gnósticos. Biblioteca de Nag Hammadi II: evangelios, hechos, cartas. Madrid: Trotta, 1999. p. 289-306.

BAZÁN, Francisco García. Evangelio de la verdad NHC I 3. In: PIÑERO, A. et al (Ed.). Traducido por Francisco García Bazán. Textos gnósticos. Biblioteca de Nag Hammadi II: evangelios, hechos, cartas. Madrid: Trotta, 1999. p. 139-161.

BAZÁN, Francisco García. Plotino y la mística de las tres hipóstasis. Buenos Aires: El hilo de Ariadna, 2011.

BERTRAND, D. A. La notion d'apocryphe dans l'argumentation de la réfutation de toutes les hérésies. In: MIMOUNI, S. C. (Dir.). Apocryphité. Histoire d'un concept transversal aux religions du livre, en hommage à Pierre Geoltrain. (Bibliothèque de l'école des hautes études sciences religieuses volumen 113). Turnhout: Brepols, 2002. p. 131-140.

BOBICHON, Ph. (Ed.). Justin Martyr, dialogue avec Tryphon. Édition critique, introduction, texte grec, traduction, commentaires, appendices, indices. Suisse: Editions Universitaires de Fribourg, 2003. (Collection Paradosis n. 47, v. I-II.).

CHARLESWORTH, J. H.; MCDONALD, L. M. (Ed.). Introduction. In: CHARLESWORTH, J. H.; MCDONALD, L. M. Non-canonical religious texts in early judaism and early christianity. New York: T\&T Clark International, 2012. p. 1-8.

CHARLESWORTH, J. H.; MCDONALD, L. M. Preface: the function of alleged noncanonical religious texts in early judaism and earliest christianity. In: CHARLESWORTH, J. H.; MCDONALD, L. M. Jewish and christian scriptures: the function of canonical and non-canonical religious texts. New York: T\&T Clark International, 2010. p. x-xii.

CRUM, W. E. (Comp.). A coptic dictionary. Oxford: Clarendon Press, 1962.

DECONICK, April D. What is cognitive historicism? Houston, 2013. Disponible en: <http://aprildeconick.com/cognitive-historicism/.>. Consultado el: 19 mayo. 2016.

ELLIOTT, J.K. The apocryphal New Testament. A collection of apocryphal christian literature in an english translation. Oxford: Clarendon Press, 2005. 
FINKELBERG, M.; STROUMSA, G. G. Introduction: before the western canon. In: FINKELBERG, M.; STROUMSA, G. G, (Ed.). Homer, the Bible, and beyond. Literary and religious canons in the ancient world. Leiden: Brill, 2003. p. 1-8.

ISENBERG, W.W. The gospel according to Philip. In: KRAUSE, M.; ROBINSON, J.M.; WISSE, F. Nag Hammadi codex II, 2-7, together whit XIII, 2*, brit. Lib. or. 4961 (1), and P. Oxy. 654, 655. (NHS XX). Leiden: Brill, 1989. p. 129-215.

REED, Annette Yoshiko. Old Testament pseudoepigrapha and post-70 judaism. In: CLIVAZ, C.; MIMOUNI, S; POUDERON, B. (Ed.). Les judaïsmes dans tous leurs états aux Ier-IIIe siècles (les Judéens des synagogues, les chrétiens et les rabbins). Actes du colloque de Lausanne, 12-14 décembre 2012. Turnhout: Brepols, 2015. p. 117-148.

KAESTLI, J.-D. La littérature apocryphe peut-elle étre comprise comme littérature au second degré (G. Genette)? In: MARGUERAT D.; CURTIS, A. Intertextualités. La Bible en echos. (Le Monde de la Bible nº 40). Genève: Labor et Fides, 2000. p. 288-304.

LE BOUlLUEC, A. (Ed.). Clément d'Alexandrie, les stromates. Stromate V, tome II. (SC 278). Traducido por P. Voulet. Paris: Cerf, 2006.

LE BOULlUEC, A. Clément d'Alexandrie, les stromates. Stromate VII. (SC 428). Traducido por Alain Le Boulluec. Paris: Cerf, 1997.

LE BOULLUEC, A. La notiond'hérésie dans la littérature grecque (I-II siècles), t. I: de Justin à Irénée. Paris: Études augustiniennes, 1985.

MARKSCHIES, Ch. The canon of the New Testament in antiquity. Some new horizons for future research. In: FINKELBERG, M.; STROUMSA, G. G (Ed.). Homer, the Bible, and beyond. Literary and religious canons in the ancient world. Leiden: Brill, 2003. p. 175194.

MIMOUNI, S. C. (Dir.). Apocryphité. Histoire d'un concept transversal aux religions du livre, en hommage à Pierre Geoltrain. (Bibliothèque de l'école des hautes études sciences religieuses volumen 113). Turnhout: Brepols, 2002. p. 1-30.

MONASTERIO BENEDICTINO SANTA MARÍA DE LOS TOLDOS. Obras de los padres de la Iglesia (152). Buenos Aires, 2015. Disponible en:

<http://www.abadialostoldos.org/patristica/obras-de-los-padres-de-la-iglesia-152.>. Consultado el: 19 mayo. 2016.

MONDÉSERT, Claude. (Ed). Clément d'Alexandrie, les stromates. Stromate I. (SC 30). Traducido por Marcel Caster. Paris: Cerf, 1951.

MUNIER, Ch. Justin. Apologie pour les chrétiens. (SC 507). Traducido por Charles Munier. Paris: Cerf, 2006.

PASQUIER, A; THOMASSEN, E. Évangile de la vérité NH I, 3; XII, 2. In: MAHE, J.-P-; POIRIER, P.-H. (Dir.). Écrits gnostiques. Paris: Gallimard, 2007. p. 43-84. 
PIOVANELLI, P. What is a christian apocrypha text and how does it work? Some obsevations on aporcryphal hermenutics. Nederlands Theologisch, Groningen, v. 50, p. 31-40, 2005 .

POUPON, G. Actes de Pierre. In: BOVON, F.; GEOLTRAIN, P. (Dir.). Écrits apocryphes chrétiens I. Paris: Gallimard, 1997. p. 1039-1114.

ROULEAU, D. Épître apocryphe de Jacques (NH I, 2). In: MAHE, J.-P-; POIRIER, P.-H. (Dir.). Écrits gnostiques. Paris: Gallimard, 2007. p. 11-41.

ROULEAU, D. L'épître apocryphe de Jacques (NH I, 2). (BCNH 18). Québec: Les presses de l'université de Laval, 1987.

ROUSSEAU, A.; DOUTRELEAU, L. Irénée de Lyon, contre les hérésies. Livre I, tome I. (SC 263). Traducido por Louis Doutreleau. Paris: Cerf, 1979.

ROUSSEAU, A.; DOUTRELEAU, L. Irénée de Lyon, contre les hérésies. Livre I, tome II. (SC 264). Traducido por Louis Doutreleau. Paris: Cerf, 1979.

ROUSSEAU, A.; DOUTRELEAU, L. Irénée de Lyon, contre les hérésies. Livre III, tome II. (SC 211). Traducido por Louis Doutreleau. Paris: Cerf, 2002.

RUBIO, Fernando Bermejo. Evangelio de Felipe (NCH II 3). In: PIÑERO, A. et al. Textos gnósticos biblioteca de Nag Hammadi II: evangelios, hechos, cartas. Madrid: Trotta, 1999. p. 15-51.

SAGNARD, F. Clément d'Alexandrie, extraits de Théodote. (SC 23). Traducido por F. Sagnard. Paris: Cerf, 1970.

SCHNEEMELCHER, W. General introduction. In: SCHNEEMELCHER, W. (Ed); WILSON, R. MCL. New Testament apocrypha. Volume one: gospels and related writings. Traducido por R. MCL. Wilson. Louisville: James Clarke \& Co, 2003. p. 9-75.

SEVRIN, J.-M-, Évangile de Thomas (NH II, 2). In: MAHE, J.-P-; POIRIER, P.-H. (Dir.). Écrits gnostiques. Paris: Gallimard, 2007. p. 297-332.

SPOSKY, E. Cognitive literary historicism. A reponse to Adler and Gross. Poetics Today, Durham, v. 24, n. 2, p. 161-183, 2003.

TARDIEU, M. Écrits gnostiques. Codex de Berlin. Traducido por Michel Tardieu. Paris: Cerf, 1984.

TORRENTS, J. M. Apócrifo de Juan. In: PIÑERO, A. et al (Ed.). Textos gnósticos. Biblioteca de Nag Hammadi I: tratados filosóficos y cosmológicos. Traducido por Josep Montserrat i Torrents. Madrid: Trotta, 2000. p. 229-258.

TROIANO, M. Padre en femenino. El Dios-madre de los gnósticos. In: VAN DEN KERCHOVE, A.; SOARES SANTOPRETE, L. (Ed.). Des oasis d'Égypte à la route de la soie - hommage à Jean Daniel Dubois. Turnhout: Brepols, 2017. p. 127-159. 
(Collection Bibliothèque de l’École des Hautes Études », série « Histoire et prosopographie).

UNIVERSIDAD DE LOS EGEOS. Culturaltec. Stromata. Mytiline, 2006. Disponible en: <http://www.aegean.gr/culturaltec/chmlab $\geq$. Consultado el: 19 mayo. 2016.

WALDSTEIN, M.; WISSE, F. The apocryphon of John. Synopsis of Nag Hammadi codices II, 1; III, 1; IV, 1 with BG 8502, 2. (NHMS XXXIII). Traducido por Michael Waldstein e Frederik Wisse. Leiden: Brill, 1995.

WILLIAMS, F. E. The apocryphon of James. In: ATTRIDGE, H. W. Nag Hammadi codex I (the Jung codex). (NHS XXII). Leiden: Brill, 1985. p. 13-53.

ZUNSHINE, L. Lisa Zunshine: Cognitive historicism. Lexington, 2011. Disponible en: <http://www.lisazunshine.net/pages/cognitive\%2ohistoricism/cognitive\%2ohistoricism.h tml>. Consultado el: 19 mayo. 2016. 